\title{
Group B streptococcal meningitis in a diabetic adult
}

\author{
Mayur Lakhani and Elizabeth A.H. Smith ${ }^{1}$
}

Department of Clinical Pharmacology and ${ }^{1}$ Department of Medical Microbiology, Ninewells Hospital and Medical School, Dundee DD1 9SY, UK.

\begin{abstract}
Summary: A rare case of adult group B streptococcal meningitis is presented. The association with diabetes mellitus is emphasized and attention is drawn to microscopic and serological confusion that may arise in differentiating it from pneumococcal meningitis.
\end{abstract}

\section{Introduction}

Group B streptococci (GBS) are an important cause of meningitis in neonates. By contrast however, there are only a few reported cases of serious GBS infection in adults (Bayer et al., 1976; Lerner et al., 1977; Stringer, 1981). Because these appear to be increasing (Stringer, 1981) we would like to describe a patient with meningitis, septicaemia, adult respiratory distress syndrome and diabetic ketoacidosis associated with GBS infection.

\section{Case history}

A 54 year old male insulin-dependent diabetic was admitted unconscious. The history obtained from his wife was of 3 days of thirst, polyuria, rigors and increasing drowsiness. He was febrile $\left(38^{\circ} \mathrm{C}\right)$, tachypnoeic and demonstrated Kussmaul's respiration. His blood pressure was $110 / 70 \mathrm{mmHg}$ and pulse 120 beats/ minute. No focal neurological deficit was present; there was no meningism. Glycosuria and ketonuria were present. Blood $\mathrm{pH}$ was $7.20 ; \mathrm{PCO}_{2} 3.7 \mathrm{kPa}$ $(28 \mathrm{mmHg}) ; \mathrm{PO}_{2} 12.8 \mathrm{kPa}(96 \mathrm{mmHg}) ;$ bicarbonate $18 \mathrm{mmol} / \mathrm{l}$; base excess -4 ; glucose $23.6 \mathrm{mmol} / 1$; sodium $149 \mathrm{mmol} / \mathrm{l}$; potassium $3.8 \mathrm{mmol} / \mathrm{l}$; chloride $103 \mathrm{mmol} / \mathrm{l}$; urea $7.0 \mathrm{mmol} / \mathrm{l}$; haemoglobin $14.3 \mathrm{~g} / \mathrm{dl}$; white cell count $12.6 \times 10^{9} / 1$ (polymorphonuclear leucocytosis). Urine microscopy and culture were negative and a chest $\mathrm{X}$-ray was normal.

Treatment was commenced with intravenous normal saline with added potassium, giving one litre in the first 30 minutes and one litre in the next hour, 2 hours and 4 hours respectively. Soluble insulin was infused intravenously at a rate of 5 units/hour. Two hours

Correspondence: M. Lakhani M.R.C.P., Department of Medicine, Addenbrooke's Hospital, Hills Road, Cambridge CB2 2QQ, UK.

Accepted: 16 April 1986 after admission, despite rehydration with 2.5 litres of saline he remained unconscious. He suffered a grand mal seizure and developed Cheyne-Stokes respiration. A lumbar puncture was performed: this revealed turbid cerebro spinal fluid (CSF) under increased pressure with white cells $1.69 \times 10^{9} / 1(50 \%$ polymorphs and $50 \%$ lymphocytes), a red cell count of $0.8 \times 10^{9} / 1$. Many Gram-positive diplococci were seen on microscopy; these were thought to be pneumococci. A direct co-agglutination test was performed using a 'Phadebact' CSF test kit (Pharmacia Diagnostics). The CSF sample was treated in a waterbath at $80^{\circ} \mathrm{C}$ for 5 minutes and the test carried out according to the manufacturer's instructions. The results were negative for Haemophilus influenzae and Neisseria meningitidis but positive for both GBS and pneumococcal antigen. Treatment was begun forthwith with intravenous benzyl penicillin $6 \mathrm{~g}$ q.i.d.

The following day cultures of the CSF grew a betahaemolytic streptococcus. This was subsequently identified as a Lancefield Group B streptococcus by its ability to produce golden pigment on Columbia agar. It was also grouped using a Streptex kit. The same organism was isolated from blood cultures taken on admission. The Streptococcal Reference Laboratory at Colindale identified the serotype as Ia polysaccharide, $\mathbf{C}$ protein.

Two further grand mal seizures occurred during the next 24 hours and phenytoin was commenced with good effect. At this stage a computed tomographic scan of the brain showed no cerebral abscesses. However, his condition deteriorated further and he developed type 1 hypoxaemic respiratory failure with $\mathrm{PO}_{2}$ of $5.4 \mathrm{kPa}(40 \mathrm{mmHg})$ and a $\mathrm{PCO}_{2} 3.4 \mathrm{kPa}$ $(25 \mathrm{mmHg})$. Multiple diffuse bilateral opacities were seen on chest X-rays for several days; these cleared only partially with frusemide. Intermittent positive pressure ventilation was commenced and required for 2 days. Thereafter he improved and 10 days later the 
CSF was normal and antibiotic therapy was stopped after 14 days. Review at 3 weeks and also at 2 months revealed no neurological or respiratory deficit. GBS.

Cultures of endo-tracheal aspirates did not grow

\section{Discussion}

Serious group B streptococcal infection (Streptococcus agalactiae) especially meningitis is rare in adults and appears to have a bimodal age distribution (Bayer $e t$ al., 1976) between young healthy females in whom infection is a complication of pregnancy and an elderly population compromised by underlying hormonal, nutritional or metabolic disease or deficiency (Bayer $e t$ al., 1976). In particular there does seem to be a close association with diabetes (Stringer, 1981; Lerner et al., 1977; Bayer et al., 1976; Gallagher \& Watanakunakorn, 1985).

Over an 8 year period in the United Kingdom

\section{References}

BAKER, C.J., KASPER, D.L. \& SCHIFFMAN, G. (1978). Specificity of the antibody response in natural infection with type III group B streptococci. In Pathogenic streptococci. Proceedings of the VII International Symposium on Streptococci and Streptococcal Diseases, Oxford 1978, Parker, M.T. (ed). pp. 150-151. Reed Books: Surrey.

BAYER, A.S., CHOW, A.W., ANTHONY, B.F. \& GUZE, L.B. (1976). Serious infections in adults due to group B streptococci. American Journal of Medicine, 61, 498.

GALLAGHER, P.G. \& WATANAKUNAKORN, C. (1985). Group B streptococcal bacteremia in a community teach-
(1975-83), $29.5 \%$ (271 cases) of all cases of neonatal meningitis were due to GBS; by contrast only $1.3 \%$ (157 cases) of adult meningitis was due to GBS (PHLS report, 1985).

Laboratory diagnosis can be confused initially by morphological similarities on microscopy between GBS and pneumococci and also by immunological cross-reactions between capsular polysaccharides of some pneumococci and the core antigen of some GBS (Baker et al., 1978). However, on culture there is no doubt as to the true nature of the organism.

It is fortunate therefore that benzyl penicillin is effective in either type of meningitis. It is worth remembering that what initially appears to be pneumococcal meningitis may in fact be GBS meningitis.

Serious GBS infections in adults carry a high mortality - up to $70 \%$ in the series reported by Gallagher \& Watanakunakorn (1985). Clinicians and microbiologists should be alert to the possibility of GBS meningitis in adults, especially diabetics.

ing hospital. American Journal of Medicine, 78, 795.

LERNER, P.I., GOPALAKRISHNA, K.V., WOLINSKY, E., MCHENRY, M.C., TAN, J.S. \& ROSENTHAL, M. (1977). Group B streptococcus (S.agalactiae) bacteraemia in adults. Medicine (Baltimore), 56, 457.

PUBLIC HEALTH LABORATORY SERVICE (PHLS) REPORT. (CDSC) (1985). Neonatal meningitis: A review of routine national data. 1975-83. British Medical Journal, 290, 778, STRINGER, J. (1981). Group B streptococcal systemic disease in Great Britain. Journal of Infection, 3, 385. 